\title{
Signaling Strength And The Announced Size Of An Open-Market Repurchase
}

\author{
W. Paul Spurlin, Mis sis sippiState University - Meridian, USA
}

\begin{abstract}
An open question exists as to whether the announced size of an open-market repurchase (OMR) possesses positive signaling effects. Relying on short sales that occur during the five trading days that follow an OMR announcement as an indication of the signaling effect of the size of the OMR program, I find that post-announcement short sales tend to decrease with positive returns surrounding OMR announcements but that post-announcement short sales do not decrease with the announced size of an OMR program. The refore, I conclude that while announcements of OMR programs serve as positive signals, in general, the announcement of a larger OMR program does not possess a stronger positive signal.
\end{abstract}

Keywords: Stock Repurchase; Short Sale; Signaling

\section{INTRODUCTION}

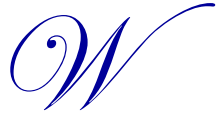
hen a firm announces an open-market repurchase (OMR) of its stock, market participants generally consider the announcement to be positive as a number of studies document rising stock prices following OMR announcements. ${ }^{1}$ As part of an OMR announcement, firms normally include the size of the program that indicates how much of their stock may be repurchased as part of the program. Comment and Jarrell (1991) and Stephens and Weisbach (1998) position this announced size of an OMR program as a managerial signal, saying that larger programs should serve as stronger positive signals to market participants. However, Chan, Ikenberry, Lee, and Wang (2010) question the reliability and credibility of OMR program size as a signal. This dichotomy as to whether the announced size of an OMR program affects the market's perception of the positive strength of an OMR announcement motivates further research.

Cook, Krigman, and Leach (2004) find that a firm's repurchase of shares increases liquidity in the firm's stock. Kadiyala and Vetsuypens (2002) argue that announcement-period returns are ambiguous as an indicator of positive signaling strength when the announced behavior increases liquidity for the stock. ${ }^{2}$ Instead of relying on price changes, they advocate using short sales as an indication of whether a corporate announcement serves as a positive signal, arguing that short sales will decrease in the post-announcement period when market participants consider the announcement to be positive.

Following Kadiyala and Vetsuypens (2002), I rely on decreasing short sales in the post-announcement period as an indication of positive signaling strength to determine whether announcements of larger OMR programs serve as stronger positive signals to market participants. Lending further evidence to the discussion of OMRs serving as positive signals, my results indicate that post-announcement short selling decreases with positive announcement period returns for OMRs. Therefore, based on evidence from short sales in the post-announcement period, I conclude that market participants view OMR announcements as positive signals, in general. However, further results indicate that the short sales in the post-announcement period do not decrease with the size of the announced OMR program. Therefore, larger OMR programs do not appear to offer stronger positive signals.

\footnotetext{
${ }^{1}$ Examples include Chan, Ikenberry, and Lee (2007); Chan, Ikenberry, and Lee (2004); and Ikenberry, Lakonishok, and Vermaelen ( 1995).

${ }^{2}$ Kadiyala and Vet suypens (2002) study stock split announcements.

Copyright by author(s); CC-B Y 
The next section of the paper offers a review of literature concerning severalimportant topics addressed by this paper. Following the literature review, I describe the empirical testing used to determine whether the announced size of an OMR serves as a positive signal to market participants. The final section discusses my findings in light of other studies and offers concluding remarks.

\section{LITERA TURE REVIEW}

\section{Open Market Repurchases and Price Increases}

An OMR announcement is required when the board of directors approves the repurchase of the firm's stock and the firm may be purchasing its own shares in the open market (Ikenberry and Vermaelen, 1996). However, Stephens and Weisbach (1998) and Jagannathan, Stephens, and Weis bach (2000) document that a significant number of repurchaseannouncing firms either repurchase no shares at all or do not repurchase enough shares to complete the announced OMR program.

Even though many firms do not complete an announced OMR program, the announcements tend to be followed by price increases. Chan, Ikenberry, and Lee (2004) and Chan, Ikenberry, Lee, and Wang (2010) find abnormal announcement-period returns of $2.2 \%$ and $2 \%$, respectively, when firms announce an OMR. Further, Chan, Ikenberry, and Lee (2004) find an exces s performance of $6.7 \%$ (including the announcement effect) in the first year after an OMR announcement is made while Chan, Ikenberry, and Lee (2007) report firms that repurchase stock during the first year after their OMR announcement outperform matched firms in each of the four years after announcement.

\section{OMR Target Ratios and Signaling}

When considering OMR announcements, the size of the repurchase is often described in terms of a target ratio that indicates the proportion of a firm's outstanding stock that will potentially be repurchased through open-market transactions. Stephens and Weisbach (1998) argue that the market's positive response to an OMR announcement is related to the announced target ratio because it proxies for the strength of management's inside information. Comment and Jarrell (1991) suggest that the target ratio of an OMR serves as a particularly strong signalbecause the target ratio serves as management's only choice variable with an OMR as compared with other repurchase methods, and they show that post-announcement returns monotonically increase in OMR target ratios. Chan, et al., (2010) argue against OMR program size as a reliable and credible signal. They question the strength of the target ratio as a positive signal because managers who do not intend to repurchase stock may use OMRs to effectively mislead investors about the quality of the firm.

\section{Short Selling around OMR Announcements}

Chan, Ikenberry, and Lee (2004) state that an interesting question is whether or not the perceived mispricing related to OMR announcements is due to public or private information, and Dittmar (2000) reports that managers engage in stock repurchases because information asymmetry between insiders and shareholders results in stocks being incorrectly priced. However, information asymmetry is likely lower between insiders and short sellers than between insiders and other public traders as Christophe, Ferri, and Angel (2004) conclude that short sellers possess superior information and that short sellers tend to make more informed decisions than other public traders.

Ikenberry and Vermaelen (1996) report that the most common explanation for firms making an OMR announcement is to signal undervaluation whereas short sellers tend to be active in a stock when its price is above its fundamental value (Diether, Lee, and Werner, 2009). However, short sellers are likely to be active in OMR stocks for two reas ons. First, some level of short selling is expected in a stock at any given time (Christophe, Ferri, and Angel, 2004). Second, according to Jagannathan, Stephens, and Weisbach (2000), firms tend to make OMR announcements after periods of poor price performance, and Christophe, Ferri, and Hsieh (2010) suggest that short sales are related to stock price momentum as stocks with declining values are aggressively shorted. 


\section{EMPIRICAL TESTING}

\section{Sample Formation}

The sample of OMR-announcing firms is taken from the SDC acquisitions database and contains firms making announcements from February 14, 2005, through December 19, 2006. ${ }^{3}$ The original number of firms identified in the SDC database as OMR firms during this period is 1,214. I eliminate 337 firms for which I am not able to obtain a measure of the number of shares or dollar amount of stock targeted in the OMR, ${ }^{4}$ and I exclude 184 firms that make more than one OMR announcement during my sample period, attempting to avoid positive signaling effects that may be attributable to a firm making multiple OMR announcements during the sample period. These two eliminations leave 693 firms in the sample. From the CRSP database, I take closing price and outstanding shares observations for each sample stock for each trading day from 25 days before the announcement to two days after the announcement. Short sales observations are taken from Regulation SHO data to obtain an observation for short sales volume occurring on each trading day during the sample period. I eliminate OMR-announcing stocks that do not have all data items available in CRSP, that are not ordinary common shares trading on either the NYSE or Nasdaq, that do not have an announcement-day, CRSP closing price of five dollars or more, and that do not have an identifiable daily short sales volume on each day over the interval of 10 days before to five days after the OMR announcement. These four requirements remove another 279 stocks from the sample. Therefore, the final sample consists of 414 OMRannouncing firms. Of these, 226 are NYSE stocks, and 188 are Nasdaq stocks. ${ }^{5}$

To determine if the sample of OMR-announcing firms exhibits abnormal holding period returns (AHPRs) during the announcement window as documented in other studies, ${ }^{6}$ AHPRs for each sample stock during the five-day announcement period surrounding the OMR-announcement day $(t=0)$ are calculated. As in Bonaimé (2012), the AHPR is measured as the holding period return for the stock over the interval $(t-2, t+2)$ less the holding period return for the CRSP value-weighted index over the same period. In Table 1, NYSE (Nasdaq) firms show mean AHPRs of about $0.38 \%(0.69 \%)$ on OMR announcement day. The also show mean AHPRs of about $0.66 \%$ and $1.27 \%$ over the five-day announcement period, respectively. The target ratios for announced OMR programs in the sample range from less than $1 \%$ to about $51 \%$ of outstanding shares for NYSE firms and from about $1 \%$ to about $44 \%$ for Nasdaq firms. The mean percentage of outstanding shares targeted for repurchase is about $8 \%$ for both NYSE and Nasdaq firms.

A short selling measure, $S S$, is calculated as the proportion of outstanding shares sold short for each sample stock on each day. I calculate abnormal short selling, ABSS, for each stock-day observation based on the trading-pattem approach used by Christophe, Ferri, and Hsieh (2010) by subtracting each stock's median value for SS over the entire sample period from the stock-day observation of SS. Table 1 shows that mean abnormal short selling during the five trading days following an OMR announcement is about $0.29 \%(0.50 \%)$ of outstanding shares for NYSE (Nasdaq) sample firms. ${ }^{7}$

\footnotetext{
${ }^{3}$ The date range of the sample is limited because post-announcement short sale datais required for testing and because I use short sale data made available by SEC Regulation SHO, which requires that intraday short sales data for NYSE and Nasdaq trading from 2005 - 2007 be made available to the public.

${ }^{4}$ When information for target size of the announced OMR program is not available in the SDC database, I search for press releases concerning the firm's OMR announcement in an effort to determine the announced OMR target.

${ }^{5}$ The full sample is used to compute univariate st atistics (Table 1), but the sample used to estimate the regression model has 391 observations because of missing dat a for independent variables. Of these 391 observations, 218 (173) are NYSE (Nasdaq) stocks.

${ }^{6}$ Since my sample consists of different firms in different time periods than the samples of previous studies, I make no direct comparisons bet ween my sample and previous samples. I only check for similarity in abnormal returns.

${ }^{7}$ It is common for studies that conduct tests using short sale observations to split the sample into NYSE and Nasdaq firms (e.g., Diether, Lee, and Werner (2009)).
}

Copyright by author(s); CC-B Y 
Table 1. Sample Summary Statistics

\begin{tabular}{|c|c|c|c|c|}
\hline Panel A: NYSE & Mean & Median & Minimum & Maximum \\
\hline $\operatorname{AHPR}_{(t=0)(\%)}$ & 0.3805 & 0.5521 & -22.2608 & 10.3109 \\
\hline $\operatorname{AHPR}_{(t-2, t+2)(\%)}$ & 0.6625 & 1.1637 & -23.4109 & 12.8881 \\
\hline Target $(\%)$ & 8.0891 & 6.4168 & 0.1757 & 51.2325 \\
\hline$A B S S(t+1, t+5)(\%)$ & 0.3466 & 0.1557 & -1.1809 & 7.7573 \\
\hline Panel B: Nasdaq & Mean & Median & Minimum & Maximum \\
\hline $\operatorname{AHPR}_{(t=0)(\%)}$ & 0.6858 & 0.5953 & -39.5815 & 20.3317 \\
\hline $\operatorname{AHPR}_{(t-2, t+2)(\%)}$ & 1.2664 & 1.2627 & -33.2216 & 21.5718 \\
\hline Target $(\%)$ & 8.0693 & 6.6436 & 1.3152 & 43.5456 \\
\hline$A B S S(t+1, t+5)(\%)$ & 0.7511 & 0.2461 & -2.0237 & 18.6092 \\
\hline
\end{tabular}

This table presents sample summary statistics. The sample includes 226 NYSE and 188 Nasdaq common st ocks that traded as ordinary common shares, that made an open-market repurchase announcement during the period of Feb. 14, 2005, to December 19, 2006, and that had a closing price of at least \$5 on announcement day. Panel A (B) includes statistics for NYSE (Nasdaq) firms. AHPR is the percentage abnormal holding period return calculated as a stock's daily return from close to close less the same-day return on the CRSP value-weighted portfolio; Target is the percentage of out standing shares announced as part of the repurchase program; and $A B S S$ is abnormal short sales calculated as the proportion of daily outst anding shares sold short less the median value of daily outstanding shares sold short for the sample period. For indexing purposes, $t=0$ is the day of the repurchase announcement.

\section{Post-Announcement Short Sales and OMR Program Size}

To empirically test the relation between post-announcement, abnormal short sales and OMR program size, ordinary least squares (OLS) is used to estimate the following regression model:

$$
\begin{aligned}
& \operatorname{ABSS}_{(t+1, t+5)}=\alpha+\beta_{1} A H P R_{(t-2, t+2)}+\beta_{2} A H P R_{(t-25, t-1)}+\beta_{3} \text { Target } \\
& +\beta_{4} H T G+\beta_{5} L T G+\beta_{6} \text { Earn_surprise }+\beta_{7} \text { Earn_Ann }_{(t-2, t+2)} \\
& +\beta_{8} \text { Earn_surprise*Earn_Ann }(t-2, t+2)+\varepsilon
\end{aligned}
$$

In model (1), the dependent variable is the sum of daily abnormal short sales calculated for the five trading days following the OMR announcement. The explanatory variables of particular interest are Target, HTG, and LTG. Target is the target ratio calculated as the number of shares announced as being potentially repurchased during the OMR program divided by the number of outstanding shares at the time of announcement. ${ }^{8}$ Following Comment and Jarrell (1991), sample stocks are separated into three groups based on target ratio size. Low-target, mid-target, and hightarget firms announce target ratios of less than $0.05,0.05$ to 0.10 , and more than 0.10 , respectively. HTG (LTG) is valued at 1 when the announcing stock is classified in the high-target (low-target) group based on OMR program size and valued at 0 , otherwise. When estimating model (1), the mid-target group serves as the omitted class such that the group of firms with target ratios of 0.05 to 0.10 serves as the base case for comparison.

\footnotetext{
${ }^{8}$ The proportion of outstanding shares targeted by the announced OMR program is referred to as target ratio or program size. These terms are used interchangeably in this paper. 
Table 2. Post-Announcement Abnormal Short Selling And OMR Program Size

\begin{tabular}{|c|c|c|}
\hline & NYSE & Nasdaq \\
\hline Intercept & $\begin{array}{l}0.0033^{* *} \\
(0.017)\end{array}$ & $\begin{array}{c}0.0012 \\
(0.645)\end{array}$ \\
\hline $\operatorname{AHPR}_{(t-2, t+2)}$ & $\begin{array}{l}-0.0551 * * * \\
(0.000)\end{array}$ & $\begin{array}{l}-0.0471 * * * \\
(0.003)\end{array}$ \\
\hline $\operatorname{AHPR}_{(t-25, t-1)}$ & $\begin{array}{l}-0.0079 * \\
(0.085)\end{array}$ & $\begin{array}{l}-0.0069 \\
(0.398)\end{array}$ \\
\hline Target & $\begin{array}{c}0.0173 \\
(0.201)\end{array}$ & $\begin{array}{l}0.0478^{*} \\
(0.068)\end{array}$ \\
\hline$H T G$ & $\begin{array}{l}-0.0024 \\
(0.139)\end{array}$ & $\begin{array}{l}-0.0009 \\
(0.790)\end{array}$ \\
\hline$L T G$ & $\begin{array}{l}-0.0022 \\
(0.105)\end{array}$ & $\begin{array}{c}0.0036 \\
(0.166)\end{array}$ \\
\hline Earn_surprise & $\begin{array}{r}0.0007 \\
(0.910)\end{array}$ & $\begin{array}{c}0.0085 \\
(0.497)\end{array}$ \\
\hline Earn_Ann $(t-2, t+2)$ & $\begin{array}{c}0.0015 \\
(0.220)\end{array}$ & $\begin{array}{c}0.0025 \\
(0.311)\end{array}$ \\
\hline Earn_surprise $*$ Earn_Ann $(t-2, t+2)$ & $\begin{array}{l}0.0361 * * * \\
(0.008)\end{array}$ & $\begin{array}{l}0.1469 * * * \\
(0.009)\end{array}$ \\
\hline $\operatorname{Adj} . R^{2}$ & 0.174 & 0.104 \\
\hline$F$ Value & $6.73 * * *$ & $3.51 * * *$ \\
\hline Observationst & 218 & 173 \\
\hline
\end{tabular}

In the OLS model, $A B S S_{(t+1, t+5)}$ serves as the dependent variable and is the sum of daily abnormal short selling during the five-day, post-OMRannouncement period. $A H P R_{(t-2, t+2)}$ is the abnormal holding period ret urn during the five-day period centered on announcement day $t=0, A H P R_{(t+}$ ${ }_{25, t-1)}$ is the abnormal holding period return during the 25 trading days occurring before announcement day. Target is the proportion of announcementday out standing shares that are potentially to be repurchased as part of the OMR program; $H T G(L T G)$ is equal to 1 if the announcing firm's target ratio is more than 0.10 (less than 0.05 ) of outstanding shares and is equal to 0, otherwise. Earn_surprise is the surprise contained in the most recent regular, quarterly earnings announcement occurring as of announcement day; Earn_Ann $n_{(t 2, t+2)}$ is equal to 1 if the earnings announcement occurs during the OMR-announcement interval of $(t-2, t+2)$ and 0 , otherwise. Estimated coefficients for NYSE and Nasdaq sample firms are listed for the tested model with p-values for st atistical significance given in parentheses below the estimate. $* * *, * *$, or $*$ indicates significance at the $1 \%, 5 \%$, or $10 \%$ level, respectively. $†$ Eight (fifteen) NYSE (Nasdaq) observations are removed from the original sample for regression estimation due to missing dat a for independent variables.

In Model (1), the inclusion of the continuous variable Target that measures target ratio, along with the dummy variables $H T G$ and $L T G$ that denote whether the target ratio is considered to be in a high or low category of target ratios adds power to the test because firms could have significantly different target ratios within each high and low group. In the sample, there are 109 observations in the high-target group $(\mathrm{HTG}=1)$. Within this group, the 10 observations with the lowest target ratios all have ratios less than 0.11 ; however, the 10 observation with the highest target ratios all have ratios greater than 0.23 , with the highest five ratios being greater than or equal to 0.40 . Even though all of these observations are in the high target ratio category, short sellers may consider target ratios of less than 0.11 to have different signaling quality than target ratios of more than 0.23 or more than 0.40 , separate from the signaling effect of being categorically high. Therefore, the regression model should simultaneously test for whether short sellers perceive positive signals when a target ratio is categorically high (above 0.10 as defined by Comment and Jarrell (1991)) and whether short sellers perceive positive signals based on absolute value of the target ratio within the categorically high group. A similar argument can be made using examples in the low target group.

Diether, Lee, and Werner (2009) demonstrate the need to control for contemporaneous and past returns when using short sales as the dependent variable in a regression. Therefore, I include $A H P R_{(t-2, t+2)}$ and $A H P R_{(t-25, t-1)}$ as independent variables. ${ }^{9}$ The inclusion of both of these variables is important. The estimated coefficient for $A H P R_{(t-2, t+2)}$ measures returns during the announcement window and serves to indicate how short sellers react to OMR announcement-period

\footnotetext{
${ }^{9}$ Other studies use regression models such that a short selling measure serves as the dependent variable while st ock return mea sures serves as independent variables (e.g., Diether, Lee, and Werner (2009) and Christophe, Ferri, and Angel (2004)) and such that the days over which short selling is measured in the dependent variable overlap with the days over which thereturn is measured in the independent variable (e.g., Christophe, Ferri, and Angel (2004) and Blau and Pinegar (2013)).
} 
returns, in general. The inclusion of $A H P R_{(t-2, t+2)}$ is based on the work of Kadiyala and Vetsuypens (2002) that suggests that abnormal short selling should decrease with positive returns as sociated with an OMR announcement if short sellers view OMR announcements as positive events. $A H P R_{(t-25,-1)}$, the abnormal holding period return for the period of 25 days before the OMR announcement is included to control for previous price movements that may be associated with short selling during the post-announcement period because Christophe, Ferri, and Hsieh (2010) explain that stocks experiencing extended periods of low returns may be aggressively shorted and because most OMR-announcing firms have recent periods of low returns (Peyer and Vermaelen, 2009). A 25 day period is chosen in an effort to measure an extended period of price movement because 25 trading days represents $10 \%$ of the approximately 252 yearly stockmarket trading days, rounded to the nearest whole day.

Ninety-eight of my 414 sample firms make an earnings announcement during the $(t-2, t+2)$ interval. Therefore, Model (1) controls for potential effects that an earnings announcement may have on abnormal short selling that occurs following the OMR announcement because earnings announcements may impact short selling that occurs around earnings announcements (e.g., Blau and Pinegar, 2013). Earn_surprise is the surprise contained in the most recent regular, quarterly earnings announcement occurring on or before the OMR-announcement day. The surprise is calculated as actual earnings minus the consensus estimate for earnings, both taken from the IBES database. Earn_Ann $(t-2, t+2)$ is equal to 1 if an earnings announcement occurs during the OMR-announcement interval of $(t-2, t+2)$ and 0 , otherwise. The interaction term between the earnings surprise variable and the variable indicating if the nearest earnings announcement is made during the OMR announcement window is included to control for the size of any earnings surprise that occurs during the OMR announcement window.

\section{Regression Results}

The OLS estimates for model (1) are presented in Table 2. Results for NYSE and Nasdaq firms show that post-OMRannouncement short sales decrease in announcement-period returns, indicating that short sellers consider OMR announcements to be positive signals, in general. However, during the five trading days that follow OMR announcements, abnormal short selling is largely not related to the size of the OMR program. Only postannouncement short sales for Nasdaq firms are significantly related to program size (at the $10 \%$ level). However, this significant positive relation indicates that short sales in Nasdaq firms do not decrease in OMR program size.

Short sales following an OMR announcement are not related to the most recent earnings announcement surprise for a firm, in general, and they are not related to whether a firm makes an earnings announcement during the same period as the OMR announcement. However, abnormal short sales immediately following an OMR announcement increase in earnings surprises that occur during the five-day OMR announcement period. Because price increases typically accompany positive earnings surprises, this result may indicate that short sellers consider positive price movements that accompany earnings surprises near an OMR announcement to be an overreaction, so they act as contrarian traders as in Diether, Lee, and Werner (2009). However, more research is needed to definitively answer this possibility.

\section{DISCUSSION AND CONCLUSION}

Stephens and Weisbach (1998) suggest that an OMR program's announced target ratio proxies for the strength of management's inside information and that the market's positive response to an OMR announcement is related to the announced target ratio. Comment and Jarrell (1991) argue that the target ratio of an OMR should serve as a strong signal to market participants because the target ratio is management's only choice variable when announcing an OMR, and they find a positive relation between the size of an OMR program and subsequent stock returns. However, Chan, et al., (2010) question OMR program size as a reliable signal.

To address this divergence in opinion of the signaling effects of OMR target ratios, I examine whether postannouncement short sales decrease with the size of an announced OMR program. My choice to use short sales following an OMR announcement to test the positive signaling quality within an OMR announcement is made based on the findings that repurchases increase liquidity in the repurchased stock (Cook, et al., (2004)). Kadiyala and Vetsuypens (2002) position announcement-period stock returns as ambiguous indicators of the signaling quality of a corporate announcement when the announced behavior increases liquidity in the stock whereas they assert that 
decreasing, post-announcement short sales are unambiguous indicators of a positive signal from a corporate announcement. My findings agree with earlier studies that show OMR announcements to have positive signaling effects, in general. However, I offer new results by showing that short sales following an OMR announcement do not decrease with the size of the OMR program and conclude that the announcement of a larger OMR program does not possess stronger positive signaling effects.

\section{ACKNOWLEDGEMENTS}

Thanks go to Brandon Cline, Ken Cyree, Chris Thomas, Bonnie Van Ness, Robert Van Ness, and two anonymous referees for comments made during the development of this paper. Remaining errors are the author's responsibility

\section{AUTHOR BIOGRAPHY}

W. Paul Spurlin is an assistant profess or of finance. His research interests include the study of financial markets and banking.

\section{REEFERENCES}

Blau, B. M.\& Pinegar, J. M. (2013). Are short sellers incrementally informed prior to earnings announcements? Journal of Empirical Finance, 21(1), 142-155.

Bonaimé, A. A. (2012). Repurchases, reputation, and returns. Journal of Financial \& Quantitative Analysis, 47(2), 469-491.

Chan, K., Ikenberry, D. L., \& Lee, I. (2007). Do managers time the market? Evidence from open-market share repurchases. Journal of Banking and Finance, 31(9), 2673-2694.

Chan, K., Ikenberry, D. L., \& Lee, I. (2004). Economic sources of gain in stock repurchases. Journal of Financial and Quantitative Analysis, 39(3), 461-479.

Chan, K., Ikenberry, D. L., \& Lee, I., \& Wang, Y. (2010). Share repurchases as a potential tool to mislead investors. Journal of Corporate Finance, 16(2), 137-158.

Christophe, S. E., Ferri, M. G., \& Angel, J. J. (2004). Short-selling prior to earnings announcements. Journal of Finance, 59(4), $1845-1875$.

Christophe, S. E., Ferri, M. G., \& Hsieh, J. (2010). Informed trading before analy st downgrades: Evidence from short sellers. Journal of Financial Economics, 95(1), 85-106.

Comment, R. \& Jarrell, G. A. (1991). The relative signaling power of dutch-auction and fixed-price self-tender offers and openmarket share repurchases. Journal of Finance, 46(4), 1243-1271.

Cook, D. O., Krigman, L., \& Leach, J. C. (2004). On the timing and execution of open market repurchases. Review of Financial Studies, 17(2), 463-498.

Diether, K. B., Lee, K. \& Werner, I. M. (2009). Short-sale strategies and return predictability. Review of Financial Studies, 22(2), 575-607.

Dittmar, A. K. (2000). Why do firms repurchase stock? Journal of Business, 73(3), 331-355.

Ikenberry, D. L., Lakonishok, J., \& Vermaelen, T. (1995). Market underreaction to open market share repurchases. Journal of Financial Economics, 39, 181-208.

Ikenberry, D. L. \& Vermaelen, T. (1996). The option to repurchase stock. Financial Management, 25(4), 9-24.

Jagannathan, M., Stephens, C.P., \& Weisbach, M. S. (2000). Financial flexibility and the choice between dividends and stock repurchases. Journal of Financial Economics, 57, 355-384.

Kadiy ala, P.\& Vetsuy pens, M. R. (2002). Are stock splits credible signals? Evidence from short-interest data. Financial Management, 31(1), 31-49.

Peyer, U. \& Vermaelen, T. (2009). The nature and persistence of buy back anomalies. Review of Financial Studies, 22(4), 16931745.

Stephens, C. P. \& Weisbach, M. S. (1998). Actual share reacquisitions in open-market repurchase programs. Journal of Finance, 53(1), 313-33. 


\section{NOTES}

